\title{
The Effects Of Hindsight Bias On Auditors' Confidence In Going-Concern Judgments And On The Audit Opinion Decision
}

Kim L. Anderson, Indiana University of Pennsylvania, USA

\begin{abstract}
This paper examines the extent to which hindsight bias influences auditors' confidence in their going-concern judgments and the resulting audit opinion decision. According to auditing standards, auditors are required to determine if substantial doubt exists regarding an audit client's likelihood of continuing as a going concern for one year from the date of the financial statements being audited. If substantial doubt does exist, an unqualified opinion modified with an explanatory paragraph describing the going-concern issue is required. Prior research indicates that auditors are prone to "hindsight bias" when making going-concern judgments. Hindsight bias is the tendency for individuals who have been provided the outcome of an event to overstate their abilities to have predicted that outcome in foresight. Prior research assumes that the presence of hindsight bias creates overconfidence and that this overconfidence will influence the audit opinion decision and will adversely affect the accuracy of subsequent probability judgments made in foresight. This assumption has never been tested, however, and non-hindsight studies found in the confidence literature suggest that the assumption might not hold true for experienced professionals, such as auditors. Using an experimental methodology, this study finds that auditors are prone to hindsight bias, but finds no evidence that this bias leads auditors to be overconfident in their going-concern judgments, nor does the bias influence their opinion decisions.
\end{abstract}

Keywords: Hindsight Bias; Going-Concern Judgments; Overconfidence; Opinion Decision

\section{INTRODUCTION}

ccording to Auditing Standards (AICPA, 1988; AICPA, 1990), auditors are required to determine if substantial doubt exists regarding an audit client's likelihood of continuing as a going-concern for one year from the date of the financial statements being audited. If it is concluded that there is substantial doubt about the client's ability to continue as a going concern, an unqualified audit opinion with an explanatory paragraph detailing the conditions creating the substantial doubt is required. This paper examines the extent to which professional auditors are overconfident in their abilities to make accurate going-concern judgments due to the presence of hindsight bias. It also examines the effects of hindsight bias on the audit opinion decision.

Hindsight bias is the tendency for individuals who have been provided with the outcome of an uncertain event to systematically overstate their abilities to have predicted that outcome in foresight (Fischhoff, 1975). Further, individuals deny that knowledge of the event's actual outcome has affected their predictions. Hindsight bias has been found to influence several audit judgments, including internal control evaluations (Reimers \& Butler, 1992), audit opinion decisions (Reimers \& Butler, 1992), preliminary analytical review judgments (Biggs \& Wild, 1985; Heintz \& White, 1989; McDaniel \& Kinney, 1994; Kennedy, 1995), and going-concern judgments (Anderson, 2000; Anderson, 2006; Kennedy, 1993; Kennedy, 1995; Maddocks, 1989).

According to the psychological literature (e.g., Fischhoff, 1975; Hawkins \& Hastie, 1990), the "knew-it-allalong" attitude created by hindsight bias creates overconfidence which impedes feedback learning, thereby reducing what individuals could potentially learn from the feedback provided by the outcome. If auditors believe they "knew 
all along" that a bankrupt company was going to fail, they will not learn what they should from the outcome and will believe more often than they should that they could have actually predicted the outcome. It is assumed that hindsight bias will cause auditors to be overconfident in their abilities to accurately make subsequent going-concern judgments in foresight and will also influence the audit opinion decision. This overconfidence may lead auditors to believe they have little reason to re-evaluate and improve their decision-making processes and evidence-gathering strategies regarding going-concern judgments.

The increasing scale of corporate bankruptcies and the current economic crisis make it more important than ever for auditors to learn from the feedback provided by actual bankruptcies and to avoid overconfidence when making these judgments. Of the 20 largest U.S. corporate bankruptcies since 1980, all but three occurred after the first quarter of 2001 with six occurring during 2009. The two largest, Lehman Brothers Holdings, Inc. and Washington Mutual, Inc. occurred during September 2008. The top five largest corporate bankruptcies for 2010 alone had total assets of $\$ 45,900,000$ (BankrupcyData.com, 2011). Also, many economists agree that the United States' economy is currently in the midst of the worst economic crisis since the Great Depression of the 1930s. This situation clearly creates the potential for a dramatic increase in the number of U.S. companies filing for bankruptcy. This places increasing pressure on auditors to accurately assess the going-concern status of their clients so that the appropriate audit opinion can be issued.

Case studies describing the facts surrounding recent U.S. bankruptcies are appearing in auditing textbooks and are being used in public accounting firm training programs (Arens, Elder \& Beasley, 2010). In order to learn as much as possible from the feedback provided by these case studies, it is critical that auditing students as well as professional auditors not be adversely affected by the presence of hindsight bias.

Prior psychological studies (e.g., Fischhoff, 1975; Synodinos, 1986; Powell, 1988; Hoch \& Loewenstein, 1989) and auditing studies (e.g., Kennedy, 1993; Kennedy, 1995; Anderson, 2000; Anderson, 2006) have assumed that hindsight bias impairs future foresight judgments by creating overconfidence. This overconfidence is assumed to exist in all situations where hindsight bias is found to exist. It is assumed that this overconfidence creates an "Iknew-it-all-along" effect which reduces what is learned from the feedback provided, thereby leading to future judgment errors.

However, it is only an assumption that hindsight bias automatically impedes feedback learning in every situation by creating overconfidence. This assumption has not been subjected to empirical testing in either the psychological or accounting literature. In fact, due to this accepted untested assumption, prior psychological (e.g., Davies, 1987) and auditing (e.g., Anderson, 2006; Kennedy, 1995) studies have focused on developing debiasing strategies aimed at reducing hindsight bias. It has been suggested that these debiasing strategies be incorporated into audit training programs, which would be costly and may be unnecessary if in fact this untested assumption that hindsight bias always leads to overconfidence is not true.

In a recent study which examines the effects of hindsight bias on jurors' evaluations of auditor negligence, Peecher and Piercey (2008) found that for relatively high Bayesian posteriors, subjects' posterior judgments about auditor negligence were objectively better in hindsight than in foresight. In other words, they found that hindsight bias is potentially functional. Peecher and Piercey did not examine whether or not hindsight bias leads to overconfidence; however, their finding that hindsight bias does not always lead to dysfunctional judgments does lend credence to the need to empirically test whether or not hindsight bias leads to overconfidence.

Confidence studies found in the psychological literature (to be discussed further in the next section) provide a theoretical basis for questioning the assumption in the hindsight literature that hindsight bias always leads to overconfidence. These studies have found a negative correlation between the level of expertise and knowledge and the degree of overconfidence exhibited. Gigerenzer (1991) and Lichtenstein \& Fischhoff, (1977) found that subjects who knew less were overconfident; whereas, subjects who knew more were underconfident. These confidence studies do not involve hindsight bias, nor do they use auditors as subjects. In addition, currently there are no auditing studies that explore the effects of hindsight bias on both auditor confidence and the resulting audit opinion decision. 
In short, determining whether or not hindsight bias does in fact cause auditors to be overconfident when making going-concern judgments is imperative in terms of guiding future hindsight research and in terms of developing cost effective audit training programs that will ultimately improve auditors' abilities to make accurate going-concern judgments. Before investing more resources toward additional hindsight debiasing research and toward altering existing auditor training programs, the assumption that hindsight bias always leads to overconfidence should be subjected to empirical testing. Further, the effects of hindsight bias on the opinion decision should also be studied. In an auditing experiment involving going-concern judgments, this paper finds no evidence that hindsight bias causes auditors to be overconfident in their going-concern judgments nor does it influence the opinion decision. In the following section, the theory behind hindsight bias and its effect on confidence is explored, and the resulting hypotheses are developed.

\section{THEORY AND HYPOTHESES}

\section{Presence of Hindsight Bias}

Fischhoff (1975) coined the term "creeping determinism" to describe the process he believed was responsible for hindsight bias. According to Fischhoff, "Upon receipt of outcome knowledge judges immediately assimilate it with what they already know about the event in question. In other words, the retrospective judge attempts to make sense, or a coherent whole, out of all that he knows about the event" $(1975$, p. 297). Because the process was hypothesized to be quick and unconscious, Fischhoff described the outcome information as "creeping" into the subject's mental representation of the event resulting in cognitive restructuring. The characteristic effect of creeping determinism is the proclivity to view a known outcome as nearly inevitable, as revealed in retrospective probability judgments, because of the seemingly unalterable sequence of events leading up to it (Hawkins \& Hastie, 1990). The "creeping determinism" hypothesis is consistent with more of the hindsight literature results than any other explanation offered (Hawkins \& Hastie, 1990).

Prior research reveals the presence of hindsight bias in several accounting settings. Financial statement users asked to assess a company's viability have been found to be prone to hindsight bias (Buchman, 1985). Jurors (Lowe \& Reckers, 1994; Kadous, 2000; Kadous, 2001) and judges (Anderson et al., 1995; Anderson et al., 1997) asked to evaluate the actions of auditors have also been found to be prone to the bias. Brown and Solomon (1987) found that capital-budgeting decisions are influenced by outcome information. In an auditing study involving internal control evaluations and audit opinion decisions, Reimers and Butler (1992) found that auditors exhibit significant (insignificant) hindsight bias when provided with surprising (unsurprising) outcome information.

Consistent with these findings, Kennedy $(1993$, 1995) first predicted that auditors are prone to hindsight bias when making going-concern judgments. This hindsight effect in an audit setting has been replicated by Anderson $(2000,2002,2006)$. Kennedy (1995) found that auditors exhibit the bias when making analytical review judgments. Anderson (2000) found that the number of years of experience does not affect the degree of hindsight bias exhibited by auditors; both experienced and inexperienced auditors are prone to hindsight bias to the same extent. These findings suggest that auditors, regardless of experience level, are prone to hindsight bias.

Based on these prior findings, this study predicts that auditors are subject to hindsight bias when making going-concern judgments. This is not an original hypothesis. However, before testing the impact of hindsight bias on auditor confidence and the opinion decision, it is first necessary to determine if the auditor subjects in this study are in fact prone to hindsight bias, which leads to the first hypothesis:

$\mathbf{H}_{1}$ : $\quad$ Auditors with outcome information will judge the reported outcome as more likely to occur than will auditors not provided with outcome information.

\section{Hindsight Bias and Overconfidence}

Past psychological research (e.g., Synodinos, 1986; Powell, 1988; Hoch \& Lowenstein, 1989) and auditing research (e.g., Kennedy, 1993; Kennedy, 1995; Anderson, 2000; Anderson, 2006) assumes that hindsight bias leads to overconfidence in probability judgments. It is argued that if individuals believe they knew all along the outcomes 
of uncertain events, then they will believe more often than they should that they could have actually predicted the outcomes (Hawkins \& Hastie, 1990). It is assumed that such overconfidence will contribute to judgment errors when a decision maker is confronted with future foresight judgments. However, this is an assumption; it has not been empirically tested.

This assumption does have some support in the confidence literature involving non-hindsight studies. In these studies, confidence in one's knowledge is usually measured by requesting subjects to answer a series of questions followed by a request to state their confidence in the correctness of their answers (Novarese, 2009; Van Den Steen, 2004; Klayman et al., 1999). In studies involving student subjects, the general finding is that subjects are overconfident, and they systematically overestimate the correctness of their answers (Rabin \& Schrag, 1999; Russo \& Schoemaker, 1992).

However, the confidence literature also finds that there is a negative correlation between the level of expertise and knowledge and the degree of overconfidence exhibited. Gigerenzer (1991) and Lichtenstein \& Fischhoff (1977) found that subjects who knew less were overconfident; whereas, subjects who knew more were underconfident. Grimes (2002) found that greater experience and knowledge lead to lower confidence. Novarese (2009) found that as knowledge and performance levels increased, subjects went from being overconfident to being underconfident. Novarese (2009) concluded that a better capacity to evaluate what one knows due to experience can cause an awareness of what one does not know, thereby creating underconfidence.

Auditors have a high level of specialized knowledge and expertise pertaining to going-concern judgments. Experience is particularly important in connection with going-concern judgments given that such judgments are typically made by highly-experienced members of accounting firms. The confidence literature suggests that this experience would lead auditors to be underconfident when making going-concern judgments. The hindsight literature, on the other hand, assumes that hindsight bias always leads to overconfidence. This countervailing effect found in the confidence literature raises questions over the assumption that auditors subject to hindsight bias will be overconfident. Therefore it needs to be empirically tested, which leads to the following hypothesis:

$\mathbf{H}_{2 \mathbf{a}}$ : Auditors with outcome information will be more confident in their probability judgments than will auditors without outcome information.

The current study also explores the extent to which the level of experience affects auditor confidence. Anderson (2000) found that the number of years of experience does not affect the degree of hindsight bias exhibited by auditors; both experienced and inexperienced auditors are prone to hindsight bias to the same extent. These findings suggest that auditors, regardless of experience level, are prone to the same amount of hindsight bias. The hindsight literature assumes that this would then lead to the same level of overconfidence between experienced and inexperienced auditors.

However, based on the findings in the confidence literature, it might be expected that the more experience auditors have, the less confidence they would exhibit. Thus, it would be expected that experienced auditors (i.e., partners and managers) would be less confident in their going-concern judgments as compared to inexperienced auditors (i.e., staff auditors). In short, the hindsight literature assumes no difference in the degree of overconfidence between experienced and inexperienced auditors, but the confidence literature suggests that inexperienced auditors would be more confident than experienced auditors. This study tests the assumption found in the hindsight literature leading to the following hypothesis:

$\mathbf{H}_{2 b}$ : Experienced auditors with outcome information will be no more or less confident in their probability judgments than will inexperienced auditors with outcome information.

If hindsight bias leads to overconfidence in probability judgments, it stands to reason that the bias would also affect decisions made based on those judgments. More specifically, if auditors with failure outcome information are overconfident in their going-concern judgments, it would be expected that they would be more likely to issue a modified audit opinion as compared to auditors without outcome information. If auditors do in fact issue a higher number of modified opinions, this would demonstrate a stronger measure of overconfidence in their 
going-concern judgments than would merely reporting that they feel more confident in those judgments. Given that only experienced auditors are involved with making the final audit opinion decisions, this study examines the effect of hindsight bias and any resulting overconfidence on the opinion decisions made by experienced auditors. This leads to the following hypothesis:

$\mathbf{H}_{2 \mathbf{c}}$ : Experienced auditors with failure outcome information will be more likely to issue a modified audit opinion than will experienced auditors without outcome information.

\section{RESEARCH METHOD}

\section{Experimental Design}

In order to test the proposed hypotheses, one experiment was conducted. The basic design used is a $2 \times 3$ factorial. The two between-subjects factors are experience and outcome. The experience factor has two levels, high (i.e., managers and partners) and low (i.e., staff auditors). The outcome factor has three levels: no outcome, (i.e., the foresight condition), failure outcome (i.e., the hindsight condition - the company files for bankruptcy), and the success outcome (i.e., the hindsight condition - the company continues in business and does not file for bankruptcy). The dependent variables are the auditor's going-concern probability judgment (hereafter referred to as a viability judgment), the auditor's confidence rating of their viability judgment, and the auditor's opinion decision.

\section{Subjects and Procedure}

The subjects were asked to judge the likelihood that a troubled company would or would not continue as a going concern. The sample of subjects consisted of 114 auditors from international public accounting firms. Given the findings in the confidence literature that there is a negative correlation between the level of expertise and knowledge and the degree of overconfidence exhibited, it is important that the current study uses auditors as subjects and not students.

Subjects were first segregated into two groups based on experience (experienced-managers and partners; inexperienced - staff auditors) and then were randomly assigned to experimental conditions. Responses to the debriefing questionnaire revealed that the mean auditing experience for the experienced (inexperienced) auditors was 9.4 (1.4) years. Each subject received a packet of materials, consisting of a sealed envelope, a page of general instructions, and either five or six pages of case data (including a case review task). After completing the case review task, the written instructions indicated that the subjects were to open the sealed envelope. The envelope contained: the outcome information (if provided), the viability judgment task, the confidence rating task, audit opinion decision task, and the debriefing task. The subjects were not allowed to use reference materials and were required to work independently. The sealed envelope approach used in this study is commonly used throughout the hindsight literature as a means of disclosing the outcome information to subjects (e.g., Maddocks, 1989; Kennedy, 1995).

\section{Case Review Task}

The subjects were provided with a page of general instructions. They also received a narrative summary of pertinent information for a real, but disguised, chemical manufacturer and three years of financial data for that manufacturer. The narrative summary contained an equal number of adverse factors (cues pointing toward failure) and mitigating factors (cues pointing toward success). The financial data included the financial statements (i.e., a balance sheet, income statement, and statement of cash flows), a summary of financial highlights, and a set of financial ratios.

Table 1 lists the experimental tasks that the subjects were asked to perform. The subjects' first task was to review the case data for Alpha Chemical, Inc. (the fictitious name given to a real chemical manufacturer). They were instructed to assume the role of audit supervisor for the most recent Alpha audit. They were also told that the fieldwork had been completed, but the final audit opinion had not yet been written. They were to review Alpha's financial statements in an attempt to assess viability. The viability judgment task was followed by a confidence rating task, an audit opinion decision task, and a debriefing task as shown in Table 1: 
Table 1: Experimental Tasks

\begin{tabular}{|c|l|}
\hline Steps & \multicolumn{1}{|c|}{ Tasks } \\
\hline I & Review Case Data (Task \#1) \\
\hline II & Failure (Success) Outcome Provided to Subjects in Failure (Success) Outcome Condition \\
\hline III & Viability Judgment Task (Task \#2) \\
\hline IV & Confidence Rating Task (Task \#3) \\
\hline V & Audit Opinion Decision (Task \#4) \\
\hline VI & Debriefing Questionnaire (Task \#5) \\
\hline
\end{tabular}

\section{Viability Judgment Task}

After reviewing the case data, subjects were instructed to begin the second task, the viability judgment. Before making their viability judgments, subjects in the failure outcome condition were informed that the company did file for bankruptcy during the last half of the year subsequent to the year under audit. Subjects in the success outcome condition were informed that the company did continue in existence as a going concern throughout the year subsequent to the year under audit. Subjects in the no outcome condition were not provided with any outcome information.

All subjects were instructed to assume that it was the last day of fieldwork for the year-end audit. They were reminded that at that time they would not have known whether the company was going to succeed or whether it was going to fail, so were told to ignore the fact that they now know the outcome. They were instructed to estimate the likelihood that the company would or would not continue as a going concern throughout the year subsequent to the year under audit by placing an "X" on a probability scale ranging from 0 percent (certain NOT to continue) to 100 percent (certain to continue).

\section{Confidence Rating Task}

Immediately following the viability judgment task, subjects were asked to rate their confidence in that judgment. Subjects were asked to rate their confidence in their viability judgment on a seven-point scale anchored on 0 , not at all confident, to 6 , extremely confident.

\section{Audit Opinion Decision Task}

After rating their confidence in their viability judgment, subjects were asked to make an audit opinion decision. They were asked, "What audit opinion do you believe should be issued to Alpha, Inc. for the year under audit?" They were given the following three choices: clean, three paragraph opinion; clean, four paragraph opinion modified for going-concern problems, or a disclaimer of opinion. Given its extreme rarity, the choice of adverse opinion was not provided.

\section{Debriefing Task}

The final task for all subjects was completing a one-page debriefing questionnaire. Subjects were asked to indicate their number of years and months of experience, their current rank within their firm (partner, manager, staff), and the number of minutes they took in completing the experiment. They were also asked to indicate both the number of audit engagements they had been associated with in which substantial doubt existed regarding the client's ability to continue as a going concern and their degree of involvement in the going-concern evaluation of these clients. In addition, they were asked to rate their degree of proficiency at evaluating a company's going-concern status. Finally, subjects in the failure outcome and success outcome conditions were asked to indicate the degree of influence, if any, the outcome information had on their viability judgments. 


\section{RESULTS}

\section{Results of Tests of Hypothesis 1}

$\mathrm{H}_{1}$ predicted that, despite instructions to ignore outcome information, auditors with outcome information would judge the reported outcome as more likely to occur than would auditors not provided with outcome information. More specifically, auditors informed that the case company failed (continued) would be more likely to judge the continued viability of the company as being less (more) likely than the auditors not provided with outcome information. The means and standard deviations for the viability judgment dependent variable are presented in Table 2. The viability judgment scale ranged from 0 percent, the company is certain not to continue, to 100 percent, the company is certain to continue. Using a 0 percent to 100 percent probability scale is commonly used in the hindsight literature dating back to Fischhoff's first studies (Fischhoff, 1975; Fischhoff, 1977).

Table 2: Means \& (Standard Deviations) of Viability Judgments by Experimental Conditions

Outcome

\begin{tabular}{|l|c|c|c|}
\hline $\begin{array}{c}\text { Experience } \\
\text { High }\end{array}$ & No & Failure & Success \\
\hline Mean & $57.37 \%$ & $55.05 \%$ & $64.42 \%$ \\
\hline Standard Deviation & 17.19 & 17.66 & 18.67 \\
\hline N & 19 & 19 & 19 \\
\hline
\end{tabular}

\begin{tabular}{|l|c|c|c|}
\hline $\begin{array}{c}\text { Experience } \\
\text { Low }\end{array}$ & No & Failure & Success \\
\hline Mean & $63.95 \%$ & $53.68 \%$ & $69.58 \%$ \\
\hline Standard Deviation & 17.12 & 16.90 & 17.00 \\
\hline N & 19 & 19 & 19 \\
\hline
\end{tabular}

\section{ANOVA Results-Interaction Effects}

To test the effect of outcome information on auditors' viability judgments, a $2 \times 3$ (experience by outcome) ANOVA was performed. The experience factor has two levels (i.e., high and low), and the outcome factor has three levels (i.e., no, failure, and success). The ANOVA results are presented in Table 3. The two-way interaction between experience and outcome is not significant $(\mathrm{p}=0.80)$. However, the main effect of outcome is significant $(\mathrm{p}=0.00)$.

Table 3: ANOVA: Experience by Outcome on Viability Judgments

\begin{tabular}{|l|c|c|c|c|c|}
\hline \multicolumn{1}{|c|}{ Source of Variation } & SS & DF & MS & F & Sig. of F \\
\hline Experience & 0.038 & 1 & 0.038 & 1.21 & 0.272 \\
\hline Outcome & 1.308 & 2 & 0.654 & 20.91 & 0.000 \\
\hline Interaction & 0.014 & 2 & 0.007 & 0.22 & 0.803 \\
\hline Error & 3.377 & 108 & .031 & & \\
\hline Total & 4.737 & 113 & & & \\
\hline
\end{tabular}

\section{Simple Main Effect Tests}

In order to determine the effect of outcome on auditor viability judgment, simple main effect tests consisting of a series of contrasts were conducted. The means contrasted are the combined means for the experienced and inexperienced auditors taken from Table 2. 
The combined mean viability judgments are summarized as follows:

No Outcome: $60.66 \%$

Failure Outcome: $54.37 \%$

Success Outcome: $67.00 \%$

In order to test $\mathrm{H}_{1}$, it is necessary to determine if the failure outcome mean viability judgment of 54.37 percent and the success outcome mean viability judgment of 67.00 percent are significantly different from the no outcome viability judgment of 60.66 percent. The failure outcome subjects' mean viability judgment of 54.37 percent is significantly less than the no outcome mean viability judgment of 60.66 percent $(\mathrm{p}=.05$, one-tail probability). This indicates that, despite instructions to ignore the outcome information, being informed that the company failed caused the subjects in the failure outcome condition to judge continued viability as less likely than did the no outcome subjects. In other words, the failure outcome subjects were prone to hindsight bias.

In addition, the success outcome subjects' mean viability judgment of 67.00 percent is significantly greater than the no outcome subjects' mean viability judgment of 60.66 percent $(\mathrm{p}=0.05$, one-tail probability). This indicates that, despite instructions to ignore the outcome information, being informed that the company continued caused the subjects in the success outcome condition to judge continued viability as more likely than did the no outcome subjects. In short, both the failure outcome and the success outcome subjects were prone to hindsight bias. This provides support for $\mathrm{H}_{1}$; auditors with outcome information judged the reported outcome as more likely to occur than did auditors not provided with outcome information.

\section{Results of Tests of Hypothesis 2}

$\mathrm{H}_{2 \mathrm{a}}$ predicted that auditors with outcome information will be more confident in their viability judgments than will auditors without outcome information. $\mathrm{H}_{2 \mathrm{~b}}$ predicted that experienced auditors will be no more or less confident in their viability judgments than will inexperienced auditors. The means and standard deviations for the confidence rating dependent variable are presented in Table 4.

Table 4: Means \& (Standard Deviations) of Confidence Ratings Experimental Conditions

\begin{tabular}{|l|c|c|c|}
\hline $\begin{array}{c}\text { Experience } \\
\text { High }\end{array}$ & No & Failure & Success \\
\hline Mean & 3.368 & 3.263 & 3.895 \\
\hline Standard Deviation & 1.423 & 1.147 & 1.449 \\
\hline N & 19 & 19 & 19 \\
\hline
\end{tabular}

\begin{tabular}{|l|c|c|c|}
\hline \multicolumn{1}{c|}{$\begin{array}{c}\text { Experience } \\
\text { Low }\end{array}$} & No & Failure & Success \\
\hline Mean & 3.368 & 3.316 & 3.895 \\
\hline Standard Deviation & 1.012 & 1.057 & 0.809 \\
\hline N & 19 & 19 & 19 \\
\hline
\end{tabular}

\section{ANOVA Results}

To test the effect of outcome information on auditors' confidence ratings, a $2 \times 3$ (experience by outcome) ANOVA was performed. The experience factor has two levels (i.e., high and low), and the outcome factor has three levels (i.e., no, failure, and success).

The ANOVA results are presented in Table 5. The two-way interaction between experience and outcome is not significant $(\mathrm{p}=.85)$. The main effect of outcome is not significant $(\mathrm{p}=.12)$ and the main effect of experience is not significant $(\mathrm{p}=.53)$. A test of homogeneity of variance was conducted and the assumption of homogeneity of variance was not rejected. 
$\mathrm{H}_{2 a}$, predicting that auditors with outcome information will be more confident in their viability judgments than will auditors without outcome information, is not supported. $\mathrm{H}_{2 \mathrm{~b}}$, predicting that experienced auditors will be no more or less confident in their viability judgments than will inexperienced auditors, is supported.

$\mathrm{H}_{2 \mathrm{c}}$ predicted that experienced auditors with failure outcome information will be more likely to issue a modified audit opinion than will experienced auditors without outcome information. The opinion decision results between the experienced auditors with failure outcome information as compared to the experienced auditors without outcome information were identical; there was no difference at all between the two groups. Of the experienced auditors with failure outcome information, $47.4 \%$ issued clean opinions, $47.4 \%$ issued modified opinions, and 5.2\% issued a disclaimer of opinion. Of the experienced auditors without outcome information, $47.4 \%$ issued clean opinions, $47.4 \%$ issued modified opinions, and 5.2\% issued a disclaimer of opinion. Thus, $\mathrm{H}_{2 \mathrm{c}}$ is not supported.

Table 5: ANOVA: Experience by Outcome on Confidence Ratings

\begin{tabular}{|l|c|c|c|c|c|}
\hline \multicolumn{1}{|c|}{ Source of Variation } & SS & DF & MS & F & Sig. of F \\
\hline Experience & 0.531 & 1 & 0.531 & 0.39 & 0.531 \\
\hline Outcome & 5.711 & 2 & 2.855 & 2.12 & 0.121 \\
\hline Interaction & 0.430 & 2 & 0.215 & 0.16 & 0.851 \\
\hline Error & 145.790 & 108 & 1.350 & & \\
\hline Total & 152.462 & 113 & & & \\
\hline
\end{tabular}

\section{CONCLUSION}

In light of the current economic crisis facing the United States, it is more important than ever for auditors to accurately assess the going-concern status of their clients and to issue the appropriate audit opinions. The purpose of this paper is to examine whether or not the presence of hindsight bias causes auditors to be overconfident in their abilities to make accurate going-concern judgments and what effect the bias has on the opinion decision. Prior hindsight studies in both the psychological and accounting literature assume that hindsight bias automatically leads to overconfidence in future foresight judgments in virtually all situations. However, this assumption has never been subjected to empirical testing. Further, the current literature focuses on the going-concern judgment and does not examine the opinion decision.

The main contribution of this study is that it does empirically test the assumption that hindsight bias leads to overconfidence, and it examines the effects of hindsight bias on the opinion decision. Using an auditing experiment involving going-concern judgments, this paper finds that, although the auditor subjects did exhibit hindsight bias as predicted, this bias did not lead the auditors to be overconfident in their judgments. In short, the current study finds no evidence of a confidence effect. It also finds that hindsight bias does not influence the opinion decision. Based on these findings, coupled with the findings in the confidence literature, the hindsight literature should exercise caution in naively assuming that hindsight bias leads to overconfidence in all situations and that this overconfidence would influence the opinion decision. Confidence is a complex construct and there are several known factors, such as existing knowledge and expertise, that exacerbate or diminish overconfidence. These factors are likely present in the case of professional auditors making going-concern judgments.

If hindsight, bias does not cause auditors to be overconfident when making going-concern judgments and does not influence the opinion decisions; then there is no need to devote resources toward changing existing audit training programs in an effort to eliminate hindsight bias as suggested by previous auditing research. It may also be unnecessary to continue conducting research studies aimed at developing debiasing strategies that eliminate hindsight bias. If hindsight bias does not lead to overconfidence and does not affect the opinion decision, it may not be as dysfunctional as previously assumed. In fact, in a recent study examining the effects of hindsight bias on jurors' evaluations of auditor negligence, Peecher and Piercey (2008) found that for relatively high Bayesian posteriors, subjects' posterior judgments about auditor negligence were objectively better in hindsight than in foresight. In other words, they found that hindsight bias is potentially functional. Future hindsight research needs to continue examining the extent to which hindsight bias is functional versus dysfunctional. It is also important that in the area of auditor judgments, future research avoids the use of student subjects. 
The results of this study must be interpreted in light of certain limitations. First, failure to find a significant confidence effect may be due to an insufficient sample size or the specific details of the experiment. Second, the study involves a sample of auditor subjects from international public accounting firms which limits the ability to generalize the results to smaller public accounting firms at the national, regional, and local levels. Third, it is difficult to determine whether the subjects were sufficiently motivated to concentrate on the experimental tasks and to complete the tasks as they would in practice. Fourth, the subjects did not have access to the array of information, resources, and consultations with others that would normally be available to them during an actual audit. Also, the subjects may not have been able to relate to many situations in practice in which they are required to ignore known outcomes and state explicitly what judgments they would have made at some point in the past.

\section{AUTHOR INFORMATION}

Kim L. Anderson is an associate professor of accounting at Indiana University of Pennsylvania teaching financial accounting. Her research interests include behavioral research in accounting, particularly the effects of cognitive biases on auditor judgments. E-mail: jckkla@ comcast.net

\section{REFERENCES}

1. American Institute of Certified Public Accountants. (1988). Statement on Auditing Standards No. 59. The Auditor's Consideration of an Entity's Ability to Continue as a Going Concern. New York, NY: AICPA.

$2 . \quad$ (1990). Statement on Auditing Standards No. 64. Omnibus Statement on Auditing Standards 1990: The Auditor's Consideration of an Entity's Ability to Continue as a Going Concern. New York, NY: AICPA.

3. Anderson, J. C., Jennings, M. M., Kaplan, S. E., \& Reckers, P. M. J. (1995). The effect of using diagnostic decision aids for analytical procedures on judges' liability judgments. Journal of Accounting and Public Policy, 14(1), 33-62.

4. $\quad$ Anderson, J. C., Jennings, M. M., Lowe, D. J., \& Reckers, P. M. J. (1997). The mitigation of hindsight bias in judges' evaluations of auditor decisions. Auditing: A Journal of Practice \& Theory, 16(2), 20-39.

5. Anderson, K. L. (2000). Hindsight bias and auditors' going-concern judgments: The effects of experience. Pennsylvania Journal of Business \& Economics, 7(1), 1-18.

$6 . \quad$ (2002). How outcome information in hindsight influences auditors' relevance ratings of adverse factors versus mitigating factors. Journal of Business \& Information Technology, 2(1), 1-13.

$7 . \quad$ _ (2006). Improving professional auditors' going-concern judgments. Pennsylvania Journal of Business \& Economics, 12(1), 1-16.

8. Arens, A. A., Elder, R. J., \& Beasley, M. S. (2010). Auditing and assurance services: An integrated approach $\left(13^{\text {th }}\right.$ ed.). Upper Saddle River, NJ: Prentice Hall.

9. BankruptcyData.com. (2009). The 20 largest public company bankruptcy filings 1980 - present. Retrieved from the Web site: http://www/bankruptcydata.com/

10. Biggs, S. F. \& Wild, J. J. (1985). An investigation of auditor judgment in analytical review. The Accounting Review, 60(3), 607-633.

11. Brown, C. E., \& Solomon, I. (1987). Effects of outcome information on evaluations of managerial decisions. The Accounting Review, 62(3), 564-577.

12. Buchman, T. A. (1985). An effect of hindsight on predicting bankruptcy with accounting information. Accounting, Organizations, and Society, 10(3), 267-285.

13. Davies, M. F. (1987). Reduction of hindsight bias by restoration of foresight perspective: Effectiveness of foresight-encoding and hindsight-irretrievability strategies. Organizational Behavior and Human Decision Processes, 40(2), 50-68.

14. Fischhoff, B. (1975). Hindsight $=$ foresight: The effect of outcome knowledge on judgment under uncertainty. Journal of Experimental Psychology: Human Perception and Performance, 1(3), 288-299.

15. __ (1977). Perceived informativeness of facts. Journal of Experimental Psychology: Human Perception and Performance, 3(2), 349-358.

16. Gigerenzer, G. (1991). How to make cognitive illusions disappear: Beyond "heuristics and biases." In W. Stroebe and Hewstone M. (Eds.), European Review of Social Psychology, (Vol. 2, pp. 83-115). Chichester, England: Wiley. 
17. Grimes, P. W. (2002). The overconfident principles of economics students: An examination of a metacognitive skill. Journal of Economic Education, 33(1), 15-30.

18. Hawkins, S. A., \& Hastie, R. (1990). Hindsight: Biased judgments of past events after the outcomes are known. Psychological Bulletin, 107(3), 311-327.

19. Heintz, J. A. \& White, G. B. (1989). Auditor judgment in analytical review - Some further evidence. Auditing: A Journal of Practice and Theory, 8(1), 22-39.

20. Hoch, S. J. \& Loewenstein, G. F. (1989). Outcome feedback: Hindsight and information. Journal of Experimental Psychology: Learning, Memory, and Cognition, 15(3), 605-619.

21. Kadous, K. (2000). The effects of audit quality and consequence severity on juror evaluations of auditor responsibility for plaintiff losses. Accounting Review, 75(3), 327-341.

22. (2001). Improving jurors' evaluations of auditors in negligence cases. Cotemporary Accounting Research, 18(3), 425-444.

23. Kennedy, J. (1993). Debiasing audit judgments with accountability: A framework and experimental results. Journal of Accounting Research, 31(2), 231-245.

24. _. (1995). Debiasing the curse of knowledge in audit judgment. The Accounting Review, 70(2), 249273.

25. Klayman, J., Soll, J.B., Gonzalez-Vallejo, C. \& Barlas, S. (1999). Overconfidence: It depends on how, what and whom you ask. Organizational Behavior and Human Decision Processes, 79(3), 216-247.

26. Lichtenstein, S. \& Fischhoff, B. (1977). Do those who know more also know more about how much they know? Organizational Behavior and Human Decision Processes, 20(3), 159-183.

27. Lowe, D. J. \& Reckers, P. M. J. (1994). The effects of hindsight bias on jurors' evaluations of auditor decisions. Decision Sciences, 25(3), 401-426.

28. Maddocks, P. M. (1989). Outcome knowledge and auditor judgment. Ph.D. Dissertation. University of Florida.

29. McDaniel, L. S. \& Kinney, W. R., Jr. (1994). Expectation-formation guidance in the auditor's review of interim financial information. Journal of Accounting Research, 32(2), 275-291.

30. Novarese, M. (2009). Past success and present overconfidence. Working Paper, Center for Cognitive Economics.

31. Peecher, M. E. \& Piercey, M. D. (2008). Judging audit quality in light of adverse outcomes: Evidence of outcome bias and reverse outcome bias. Contemporary Accounting Research, forthcoming.

32. Powell, J. L. (1988). A test of the knew-it-all-along effect in the 1984 presidential statewide elections. Journal of Applied Psychology, 18(4), 760-773.

33. Rabin, M. \& Schrag, J. L. (1999). Impressions matter: A model of confirmation bias. Quarterly Journal of Economics, 114(1), 37-82.

34. Reimers, J. L. \& Butler, S. A. (1992). The effect of outcome knowledge on auditors' judgmental evaluations. Accounting, Organizations and Society, 17(2), 185-194.

35. Russo, J. E. \& Schoemaker, P. J. H. (1992). Managing overconfidence. Sloan Management Review, 16(4), 7-17.

36. Synodinos, N. E. (1986). Hindsight distortion: "I-knew-it-all-along and I was sure about it." Journal of Applied Social Psychology, 16(2), 107-117.

37. Van Den Steen, V. (2004). Rational overoptimism (and other biases). American Economic Review, 94(4), 1141-1151. 
NOTES 